\title{
DA FORMAÇÃO DO RESERVATÓRIO À CRIAÇÃO DA PLATAFORMA DE ENERGIAS RENOVÁVEIS: 40 ANOS DE ESTRATÉGIAS AMBIENTAIS DA HIDRELÉTRICA BINACIONAL DE ITAIPU
}

\author{
Sigrid de Mendonça Andersen ${ }^{98}$ \\ Marcela Valles Lange ${ }^{99}$
}

\section{RESUMO}

Concebido como um empreendimento para a geração de energia elétrica no rio Paraná, a construção da Itaipu Binacional deu-se durante os governos militares do Brasil e do Paraguai, na década de 1970. O fechamento das comportas do canal de desvio, em 1982, gerou o grande lago de Itaipu, com 1.350 km² $^{2}$ de extensão, causando enormes impactos ao meio físico, biótico e antrópico, alterando a geografia do oeste do Paraná e inundando grandes porções de matas nativas no território paraguaio. Ao longo desses 40 anos de existência, é possível contextualizar as estratégias ambientais desta empresa, identificando quatro fases distintas. O presente artigo descreve essas fases, que tiveram início em 1975 e se atualizam na recente criação da Plataforma Itaipu de Energias Renováveis, em 2008, que se destaca por desenvolver projetos de estímulo ao emprego de fontes de energias renováveis solar, eólica, de biomassa e hidráulica. Hoje, a Plataforma e o Centro Internacional de Hidroinformática $(\mathrm{CIH})$ são apoiados por uma cátedra da UNESCO sobre o Nexo Água e Energia no Programa de Pós Graduação em Meio Ambiente e Desenvolvimento da Universidade Federal do Paraná.

\footnotetext{
98 Graduada em Ciências Sociais pela Universidade Federal do Paraná, Doutora em Geografia e Ciências Ambientais pela Universidade de Aberdeen, Escócia, Professora no Programa de PósGraduação em Meio Ambiente e Desenvolvimento (PPGMADE) da Universidade Federal do Paraná, sigridandersen56@gmail.com.

99 Graduada em Ciências Biológicas pela Universidade Federal do Paraná e Tecnologia em Química Ambiental pela Universidade Tecnológica Federal do Paraná, Mestre em Engenharia Mecânica e de Materiais pela Universidade Tecnológica Federal do Paraná, Doutoranda no Programa de PósGraduação em Meio Ambiente e Desenvolvimento (PPGMADE) da Universidade Federal do Paraná, marcelavlange@gmail.com.
} 
PALAVRAS-CHAVE: Itaipu; Estratégia ambiental; Energias renováveis; Modelo de gestão.

\section{INTRODUÇÃO}

Quarenta anos se passaram desde o início da construção da Usina Hidrelétrica de Itaipu, projeto concebido na década de 1970 que aproveita o potencial hidráulico do rio Paraná, no trecho contiguo aos territórios do Brasil e do Paraguai. O local da barragem está a 23,5 km da foz do rio Iguaçu que, por sua vez, estabelece o limite de fronteira entre o Brasil e a Argentina.

A construção da represa começou em janeiro de 1975. Em 1982, as comportas do canal de desvio foram fechadas, gerando o grande lago de Itaipu, com $1.350 \mathrm{~km}^{2}$ de extensão, e causando enormes impactos ao meio físico, biótico e antrópico, alterando a geografia regional. Em 14 dias o lago de Itaipu já estava formado pela vazão do rio Paraná. No dia 5 de maio de 1984, a primeira unidade geradora de Itaipu foi acionada. Hoje, com uma capacidade instalada de 14.000 MW e 20 unidades geradoras de $700 \mathrm{MW}$ cada, a Itaipu é a maior produtora mundial de hidroeletricidade, tendo produzido mais de 2,2 bilhões de MWh desde o início de sua operação até o final do ano de 2014 , contribuindo para cerca de $17 \%$ da energia elétrica consumida no Brasil e 75\% no Paraguai (ITAIPU BINACIONAL, 2010).

\section{AS ESTRATÉGIAS AMBIENTAIS DE ITAIPU: 1975-2015}

A origem da palavra estratégia deriva no termo grego strategia, que significa plano, método e manobras para alcançar um objetivo ou resultado específico. Neste trabalho, estratégia ambiental refere-se à ação planejada, considerando a escala geográfica de atuação, as condicionantes ambientais, os avanços dos marcos ambientais internacionais e a evolução da legislação ambiental, e ao modelo de gestão adotado, coadunando-se aos objetivos centrais da empresa ou ampliando-os ao incorporar novas políticas, planos, programas e projetos.

Sabe-se que, na época da celebração do Tratado de Itaipu (BRASIL, 1973) ainda era relativamente incipiente no mundo a conscientização quanto à importância da preservação ambiental. Essa circunstância pode explicar o fato de não existir, no tratado de Itaipu, qualquer disposição sobre o meio ambiente, nem ter sido celebrado R. gest. sust. ambient., Florianópolis, n. esp, p.378-393, dez. 2015. 
protocolo adicional sobre esse aspecto.

Além disso, na década de 70, não havia a obrigatoriedade da elaboração dos Estudos de Impacto Ambiental (EIA), previamente à implantação de empreendimentos. No Brasil, a legislação sobre a matéria foi estabelecida a partir da Lei 6.938/81 (BRASIL, 1981), que institui a Política Nacional do Meio Ambiente, e complementada pela Resolução CONAMA 001/86 (CONAMA, 1986). No Paraguai, a legislação sobre a avaliação de impactos ambientais só foi aprovada em 1993, induzindo um novo referencial às ações de desenvolvimento no âmbito governamental e da iniciativa privada.

O primeiro EIA no Brasil foi realizado em 1972 para represas hidrelétricas e reservatórios financiados pelo Banco Mundial e por exigência do próprio Banco. A Itaipu foi financiada por bancos privados internacionais e sem cláusulas ambientais. Devido à magnitude desta obra hidrelétrica e sem os estudos prévios necessários, os impactos ao ambiente físico, biológico e social foram diversos, sendo monitorados até os dias de hoje e com diferentes abordagens.

\subsection{Fase do reconhecimento dos efeitos ecológicos do projeto (1971-1981)}

A primeira consideração ambiental em relação à Usina Hidrelétrica de Itaipu teve início em 1971, quando o Comitê Executivo da Comissão Mista Técnica de Itaipu autorizou a contratação de um "renomado ecólogo independente" para desenvolver os primeiros estudos, contando com a assistência de engenheiros especialistas da IECO - International Engeneering Co. INC., com sede em São Francisco, Califórnia, e da ELC - Electroconsult, de Milão, Itália, com experiência em avaliação de efeitos ambientais causados por grandes aproveitamentos de recursos hidráulicos. Coube ao norte-americano Dr. Robert Goodland, consultor ambiental do Banco Mundial, abordar os tópicos de ecologia, arqueologia, socioeconômica e história, enquanto os especialistas da IECO-ELC tratavam dos temas relacionados à engenharia, geologia e hidrologia.

O relatório "Reconhecimentos dos Efeitos Ecológicos do Projeto" (COMISSÃO MISTA TÉCNICA BRASILEIRO-PARAGUAIA, 1973), elaborado pela equipe internacional e publicado em abril de 1973, é um sucinto documento que, após breve diagnóstico, aponta quais seriam as mudanças importantes e as secundárias geradas pela construção da hidrelétrica. Dentre os importantes e inevitáveis, inclui o R. gest. sust. ambient., Florianópolis, n. esp, p.378-393, dez. 2015. 
desaparecimento do trecho de $170 \mathrm{~km}$ do rio Paraná, que se transformaria em lago, e a submersão dos Saltos de Sete Quedas. "Se bem que esses saltos sejam únicos e possuam um grande valor intrínseco, são desconhecidos ou ignorados na América Latina", aponta o relatório (p. IV-1).

Dentre as mudanças de menor importância, surpreendentemente julgadas como "secundárias" e também inevitáveis, constam a diminuição do habitat de animais e aves, a inundação de $700 \mathrm{~km}^{2}$ de florestas virgens, o alagamento de mais de 600 $\mathrm{km}^{2}$ de terras agrícolas e a inundação de alguns locais de interesse arqueológico. Como medida de compensação, o relatório propõe a construção de um grande parque internacional nas duas margens do lago, mais ampliado em território paraguaio, devido à presença de matas nativas ainda preservadas. $O$ parque internacional, no entanto, nunca foi criado.

\subsection{O plano básico de conservação do meio ambiente (1975-1982)}

O relatório dos consultores internacionais balizou o "Plano Básico de Conservação do Meio Ambiente" (ITAIPU BINACIONAL, 1975), levado a cabo por uma equipe de profissionais brasileiros e paraguaios da Itaipu e igualmente responsáveis pela sua execução. Pelo regimento interno da empresa, coube à Diretoria de Coordenação da Entidade Itaipu Binacional os tratos sobre o meio ambiente, ou seja, as medidas de prevenção, correção e conservação dos recursos naturais e das condições sanitárias na área de aproveitamento hidrelétrico do reservatório.

O engenheiro florestal Arnaldo Müller, que assumiu o Departamento de Meio Ambiente, criado no âmbito da Diretoria de Coordenação da Itaipu Binacional, conta que tinha pouco mais de quatro anos de formado quando recebeu, em 1975, o convite para chefiar as ações de meio ambiente na parte brasileira de Itaipu, permanecendo ali até 1991.

Durante um mês, e com equipe formada por três colegas, elaborou o Plano Básico para diagnosticar os impactos do enchimento do reservatório e, nos 15 anos seguintes, teve de lidar com a instabilidade política e econômica da empresa Itaipu para pôr em prática os projetos de atenuação dos impactos. Reconhece que a questão ambiental era considerada supérflua na visão progressista do governo militar da época e foi uma das menos privilegiadas no período de construção da usina R. gest. sust. ambient., Florianópolis, n. esp, p.378-393, dez. 2015. 
"Falar em proteger o verde era uma espécie de poesia para os militares. Nosso presidente da época (general Ernesto Geisel) não era simpático à questão, então a preocupação maior era com o reservatório em si e com o processo de desapropriação"1, diz Muller. "Em alguns aspectos, era um trabalho para inglês ver, em função da pressão externa provocada pela Conferência de Estocolmo (1972). Nas condições que tínhamos, acho que fizemos o possível"100, complementa.

$\mathrm{Na}$ ausência de legislação ampla sobre a matéria, a única lei em vigor era o Código Florestal (BRASIL, 1965), que exigia uma Área de Proteção Permanente (APP) de 100 metros em volta do reservatório. Muller, entretanto, conta que havia uma oposição muito forte do setor elétrico no caso da Itaipu, "pois muitos achavam que não havia necessidade de replantar aquela área toda"1. Foi o diretor jurídico da época, Paulo José Nogueira da Cunha, que se posicionou firmemente para que o Código Florestal fosse cumprido.

O "Plano básico de Conservação do Meio Ambiente" (ITAIPU BINACIONAL, 1975) ordenou as ações ambientais em três campos inter-relacionados: os meios físicos, bióticos e sociais, estes últimos compreendendo os aspectos culturais, de arqueologia, a história, o uso múltiplo e potencial, as endemias rurais e o saneamento. As questões vinculadas às desapropriações e relocações foram tratadas por outras estruturas da Itaipu. Os inventários e levantamentos nesse período foram apresentados no $1^{\circ}$ Seminário de Itaipu sobre Meio Ambiente, realizado em Assunção, em 1979. O Plano Básico foi substituído, em 1982, pelo Plano Diretor da Área do Reservatório (ITAIPU BINACIONAL, 1982).

\section{IMPACTOS AMBIENTAIS DE ITAIPU}

Por conta de seu tamanho e capacidade, e sem os estudos prévios mais amplos e aprofundados, a Itaipu testemunhou impactos ambientais colossais. Os impactos sobre a vegetação natural e espécies da fauna ocorreram nos estágios iniciais do projeto, com a formação do lago. Sem recursos apropriados para grandes ações e não prevendo a rapidez no enchimento do reservatório, funcionários do meio ambiente desenvolveram um sistema de resgate de fauna chamado de Mymba Kuera ("caçabicho" em tupi guarani).

100 Entrevista para o jornal O Estado de São Paulo em 28 de novembro de 2012.

R. gest. sust. ambient., Florianópolis, n. esp, p.378-393, dez. 2015. 
$\mathrm{Na}$ medida em que o reservatório foi enchendo, os animais foram sendo resgatados. Para essa operação, cinco bases foram instituídas, com 17 barcos e 16 equipes. Muller (1985) contabiliza 9.235 exemplares de animais resgatados na margem brasileira e 24.753 no lado paraguaio, totalizando 33.988 animais, dentre eles 2.400 cobras venenosas que foram enviadas, em grande parte, de caminhão ao Instituto Butantã, em São Paulo.

As Sete Quedas, uma série de cascatas correndo em cânions de rochas basálticas escuras e de grande beleza cênica, foram gradualmente desaparecendo. Depois foram os solos - um dos solos mais férteis da bacia do Prata - e as terras cultivadas. Da área total inundada, mais de $700 \mathrm{~km}^{2}$ eram cobertos por florestas subtropicais nativas, a chamada Mata Atlântica Interior ou Selva Paranaense. Estimase que $91 \%$ da área inundada no Paraguai estivesse coberta de vegetação nativa. Muller (1985) avalia que, originalmente, a região continha 213 espécies de árvores e 463 espécies botânicas, segundo inventário feito em 1977 pela Fundação de Pesquisas Florestais do Paraná.

Alterações no curso do rio Paraná tiveram impactos diretos sobre a fauna aquática. A interrupção das rotas migratórias reprodutivas dos peixes causou uma redução de aproximadamente 20 espécies. Estudos realizados em 1977, antes da formação do lago, identificaram 129 espécies de peixes no trecho entre as Sete Quedas e Foz do Iguaçu.

Os impactos negativos sobre a população de peixes e sua composição causaram prejuízos para pescadores artesanais e comerciais que dependiam da piscicultura como uma fonte significativa de proteína em suas comunidades ribeirinhas. Souza e Mills (1995) apontam outros impactos após a formação do reservatório e que dizem respeito às alterações microclimáticas, como um aumento na velocidade do vento, na temperatura e na umidade da região.

A compra de terra exigida pela Itaipu incluía 8.500 propriedades, das quais 6.900 eram rurais e 1.600 urbanas, no lado brasileiro. Do lado paraguaio, estima-se que 1.324 expropriações foram feitas para realocar famílias que viviam próximas ao rio Paraná e pequenos tributários.

As desapropriações na área foram realizadas de 1975 a 1981 (ITAIPU BINACIONAL, 1991). As terras inundadas geraram prejuízos para a economia regional e causaram impactos sociais em larga escala, visto que $86,1 \%$ das propriedades do lado brasileiro pertenciam a pequenos proprietários, numa média de R. gest. sust. ambient., Florianópolis, n. esp, p.378-393, dez. 2015. 
18 a 20 hectares cada uma.

Com o preenchimento do reservatório de Itaipu, os municípios limítrofes, do lado brasileiro, tiveram aproximadamente 11.300 hectares inundados. A infraestrutura existente, como armazéns, silos, estradas, escolas, igrejas e cemitérios, se perdeu, causando prejuízos econômicos significativos. Medidas compensatórias foram tomadas apenas com a criação da Lei dos Royalties (BRASIL, 1989).

\subsection{Fase de mitigação, compensação e apoio ao desenvolvimento regional (1982-1990)}

O Plano Diretor da Área do Reservatório de Itaipu, instituído em 1982, recomendava, além das medidas e programas para atenuar os impactos diretos e indiretos da Itaipu, causados pela formação do reservatório, aprimorar as possibilidades de usufruto do reservatório e do seu entorno a toda a população adjacente (ITAIPU BINACIONAL, 1982).

A estratégia ambiental da Itaipu, nessa fase, incluía, pela primeira vez, o comprometimento com a inserção do empreendimento no desenvolvimento regional. Com isso, vários projetos de infraestrutura foram projetados e implantados nos municípios lindeiros, fossem eles de caráter ambiental ou não. Surgem, então, os complexos públicos de lazer, como praias, marinas e portos às margens do lago de Itaipu, atraindo a população lindeira e turistas, os projetos de captação de água para abastecimento urbano, industrial e agropecuário e benfeitorias, como salas de aula, canchas esportivas, estradas e pontes.

O pagamento dos royalties pela Itaipu tornou-se outro grande marco neste período, viabilizado pela publicação da Lei Federal 7.990/89 (BRASIL, 1989), que estabelece o valor a ser pago pelas concessionárias de serviços energéticos, e pela Lei 8.001/90 (BRASIL, 1990), que define as porcentagens para a distribuição mensal da compensação financeira.

Com essas leis, a distribuição compensatória da Itaipu destinou 45\% dos recursos ao estado do Paraná, $45 \%$ aos municípios diretamente atingidos pelo reservatório e de forma proporcional à área inundada, e 10\% para órgãos federais. $A$ lei de compensação envolve o pagamento mensal de royalties pela entidade de Itaipu a cada um dos países parceiros - Brasil e Paraguai - para uso das águas do rio Paraná para a produção de energia elétrica (SOUZA; MILLS, 1995).

R. gest. sust. ambient., Florianópolis, n. esp, p.378-393, dez. 2015. 
De 1985 até 2013, a empresa pagou cerca de US\$ 9 bilhões em royalties aos dois países (ITAIPU BINACIONAL, 2010). Hoje, essa prodigiosa fonte de renda tem um papel crucial no desenvolvimento social e econômico da região.

\subsection{O plano diretor da área do reservatório de Itaipu (1982)}

O Plano Diretor da Área do Reservatório de Itaipu (ITAIPU BINACIONAL, 1982) recomendou, além das diretrizes e políticas ambientais da empresa, 21 programas em conjunto com o Paraguai. Dentre os mais importantes, podem ser citados a consolidação da faixa de proteção do lago ${ }^{101}$, com o reflorestamento de suas margens e dos rios tributários, e o estímulo à conservação de solos e ao manejo de micro bacias hidrográficas, com vistas a combater a contaminação por agrotóxicos e a sedimentação do lago, desta forma, contribuindo para aumentar a expectativa de vida útil da usina (MULLER, 1982).

O reinventário da ictiofauna, o monitoramento da fauna aquática e projetos de aquicultura foram outros programas implantados. Com o objetivo de preservar a fauna e flora remanescentes, foram criadas as reservas e refúgios biológicos. É nessa fase que se cria o Ecomuseu de Itaipu (Brasil) e o Museu de História Natural (Paraguai), com finalidade educativa. Em outubro de 1987, é realizado o Segundo Seminário Itaipu Binacional sobre Meio Ambiente, registrando avanços e buscando soluções a problemas identificados até aquele momento.

Sob a administração de Ney Braga, como diretor brasileiro da Itaipu binacional (1985-1990), a diretoria de meio ambiente é alçada ao nível de Superintendência, encarregada de executar o Plano Diretor da Área do Reservatório e os novos desafios. A Superintendência de Meio Ambiente (SMA) chegou a contar com 243 funcionários, sendo 47 pertencentes diretamente ao quadro da Itaipu Binacional, apresentando uma nova estratégia ambiental ao fornecer as bases operacionais para o cumprimento do Plano Diretor.

Ao final de 1990, os cortes orçamentários e a não assinatura de contratos previstos nas rubricas aprovadas tornam-se rotina, protelando projetos ambientais importantes e serviços terceirizados nas áreas de limnologia, biologia pesqueira,

${ }^{101}$ A faixa de proteção foi implantada na orla do reservatório, com largura média de 227 metros. É formada pelas faixas de segurança, com 5 metros de elevação, até a cota $222 \mathrm{~m}$ chamada maximummaximorum, e a de preservação permanente (APP), com 100 metros a partir da cota $225 \mathrm{~m}$.

R. gest. sust. ambient., Florianópolis, n. esp, p.378-393, dez. 2015. 
arqueologia e fiscalização florestal (SMA/ITAIPU, 1990). Esses cortes vão ter reflexos nos anos posteriores.

\subsection{Fase de alteração na área de influência do reservatório e desaceleração dos programas ambientais (1990-2002)}

No início dos anos 1990, com as dificuldades financeiras do país e da empresa, predominou a mentalidade de que a Itaipu deveria preocupar-se apenas com a geração de energia e grande parte dos funcionários da área ambiental foi demitida. Pensou-se, naquela época, em repassar os refúgios biológicos para as universidades locais, o que acabou não ocorrendo (O ESTADO DE SÃO PAULO, 2012).

O então coordenador de meio ambiente aquático da Itaipu Binacional, o biólogo J. R. Borghetti, assume a Superintendência de Meio Ambiente, centrando suas ações no campo da limnologia, biologia pesqueira, nutrição de peixes e sedimentometria, suas áreas de conhecimento, e dedica-se a implantar o projeto de migração de peixes (o Canal de Desova), além de apoiar programas de educação ambiental.

Outros programas anteriormente implantados sofrem cortes orçamentários e são desacelerados. Borguetti busca, ainda, uma maior inserção internacional da Itaipu Binacional junto a organizações sul-americanas como o MERCOSUL e fóruns ambientais dos países da Bacia do Prata.

A alteração mais significativa desta fase diz respeito à delimitação de uma nova Área de Influência do Reservatório, justificada para melhor avaliar e redirecionar o alcance das ações da empresa. A Itaipu Binacional optou por dividir a Área de Influência em: (1) Área de Influência Interativa e (2) Área de Influência Ambiental.

A Área de Influência Interativa correspondia ao ambiente contíguo às áreas protegidas, compreendendo quatro municípios lindeiros do Departamento de Alto Paraná e três de Canindeyú, no Paraguai, e os quinze municípios lindeiros do estado do Paraná, e um do Mato Grosso do Sul, no Brasil, onde se julgava que a Itaipu exercia e recebia influências diretas.

A Área de Influência Ambiental correspondia às áreas das microbacias de contribuição direta ao reservatório de Itaipu, em ambas as margens, "onde a Itaipu Binacional não exercia influência”, mas de onde recebia todo o impacto do uso do solo e do desenvolvimento econômico (ITAIPU BINACIONAL, 2000).

R. gest. sust. ambient., Florianópolis, n. esp, p.378-393, dez. 2015. 
Sabe-se que a Itaipu recebe uma forte influência de tudo o que acontece na bacia superior, águas acima do reservatório, os chamados efeitos efluentes, e que estes, em maior grau, incidem nas águas abaixo da represa. Esse recorte ou escala geográfica de gestão vai ser novamente alterado na administração de Jorge Miguel Samek (2003-2015), marcando uma nova e recente fase da estratégia ambiental da Itaipu.

\subsection{Fase do paraná 3 como área de influência direta do reservatório, gestão participativa e estímulo às energias sustentáveis e renováveis (2003-2015)}

Jorge Samek assume a diretoria geral da Itaipu Binacional, a mais longeva administração da história de Itaipu, com o propósito de "gerar energia elétrica de qualidade, com responsabilidade social e ambiental, impulsionando o desenvolvimento econômico, turístico e tecnológico sustentável, no Brasil e no Paraguai".

Lança o programa "Cultivando Água Boa", envolvendo atores locais como associações comunitárias, órgãos governamentais, ONGs, instituições de ensino, cooperativas, empresas e a comunidade. No Cultivando Água Boa, concebido pelo engenheiro agrônomo Cícero Bley, a escala geográfica de atuação ambiental se amplia significativamente ao considerar toda a Bacia do Paraná 3 (figura 1), com seus mais de oito mil km², como Área de Influência Direta do reservatório, abarcando 29 municípios ${ }^{102}$. A gestão por bacia hidrográfica é a estratégia ambiental adotada nesta fase, e abrange 70 projetos e subprojetos em várias microbacias que alimentam o reservatório da usina.

Figura 1: Bacia do rio Paraná 3: Localização e hidrografia

\footnotetext{
102 Foz do Iguaçu, Santa Terezinha de Itaipu, São Miguel do Iguaçu, Itaipulândia, Medianeira, Matelândia, Céu Azul, Ramilândia, Santa Helena, Diamante do Oeste, São Jose das Palmeiras, Entre Rios do Oeste, Pato Bragado, Ouro Verde do Oeste, São Pedro do Iguaçu, Santa Tereza do Oeste, Cascavel, Marechal Cândido Rondon, Toledo, Maripá, Nova Santa Rosa, Quatro Pontes, Mercedes, Terra Roxa, Guaíra, Altônia, Missal, Vera Cruz do Oeste e Mundo Novo-MS.

R. gest. sust. ambient., Florianópolis, n. esp, p.378-393, dez. 2015.
} 


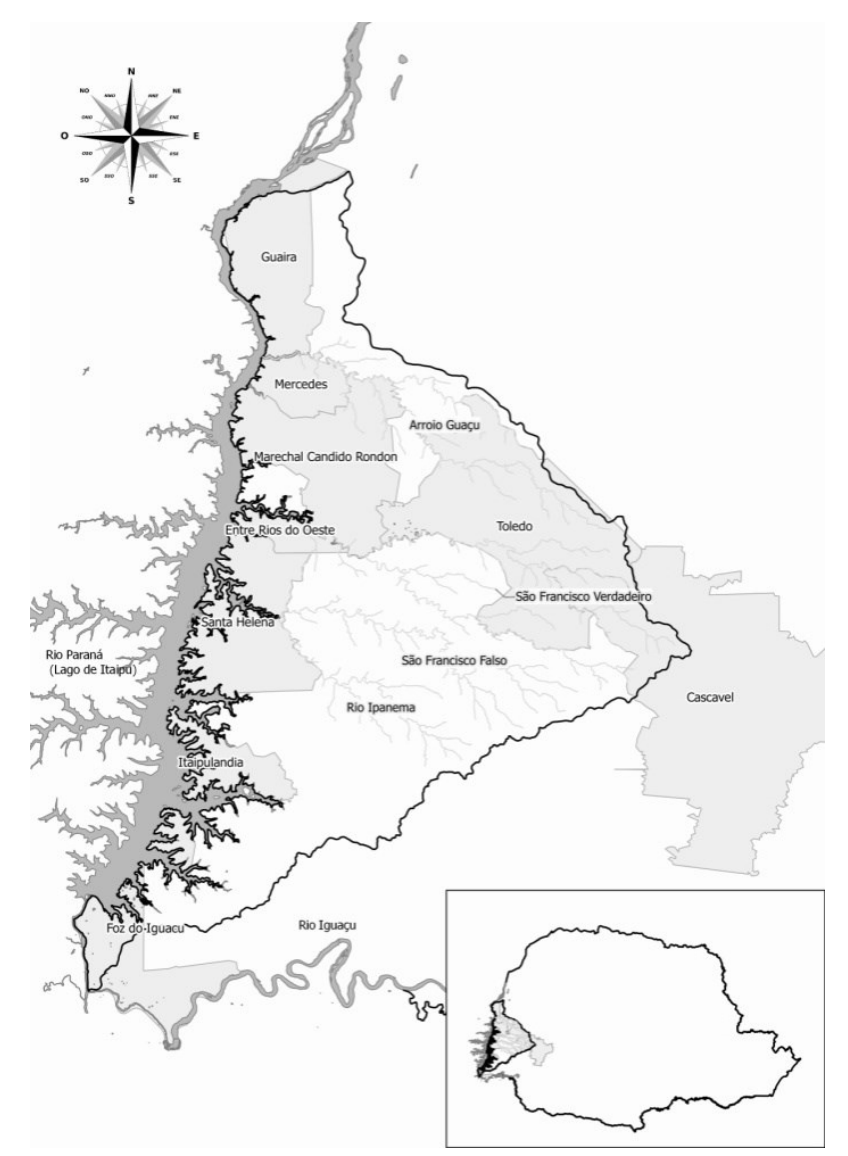

Fonte: Centro Internacional de Hidroinformática

O modelo de gestão adotado assenta-se em quatro metodologias: (1) gestão ambiental com a adoção dos procedimentos baseados na Norma ISO 14.001; (2) gestão territorial para investigar, organizar e fornecer as informações sobre cada área do território das ações do programa; (3) gestão participativa e (4) gestão por programas. Os programas buscam o alinhamento com os compromissos internacionais, como a Carta da Terra, as Metas do Milênio, a Agenda 21, o Tratado de Educação Ambiental para Sociedades Sustentáveis e o Protocolo de Kyoto sobre mudanças climáticas.

Considerando a complexa gestão das relações entre a sociedade e o meio físico nas bacias hidrográficas, na época da elaboração do Programa Cultivando Água Boa, identificou-se a necessidade da adequada gestão de informações para possibilitar a tomada de decisão e o planejamento. Desenvolveu-se, a partir de então, um amplo Cadastro Técnico Multifinalitário (CTM), construído com a função de promover e facilitar a integração matricial dos dados e informações com as características territoriais das propriedades imobiliárias - geradoras de aspectos

R. gest. sust. ambient., Florianópolis, n. esp, p.378-393, dez. 2015. 
ambientais - e das bacias hidrográficas - receptoras de impactos ambientais (BLEY JUNIOR, 2006).

A criação do CTM impulsionou, em 2006, a concepção do Centro Internacional de Hidroinformática $(\mathrm{ClH})$, resultado da parceria entre a Itaipu Binacional e o Programa Hidrológico Internacional da UNESCO, tornando-se referência em hidroinformática aplicada à gestão das águas. De forma interdisciplinar, o sistema desenvolvido pelo $\mathrm{ClH}$ traz uma nova abordagem para a gestão integrada de bacias hidrográficas, reunindo informações de cunho econômico, social e ambiental que podem ser visualizadas, permitindo que os tomadores de decisão, ou seja, os comitês de bacias, prefeituras, órgãos ambientais, entre outros, direcionem as ações para a gestão da mesma perante as deficiências identificadas (DIAS et al., 2014).

O CIH encontra-se no Parque Tecnológico de Itaipu (PTI), criado em 2004, para o desenvolvimento de pesquisas e a implantação de novas tecnologias, principalmente aquelas voltadas à produção de energias renováveis. O objetivo é contribuir para o desenvolvimento regional, articulando e fomentando ações voltadas ao desenvolvimento econômico, científico e tecnológico. Instalado nos antigos alojamentos dos operários que construíram a usina de Itaipu, o PTI vem desenvolvendo pesquisas sobre veículos elétricos e o uso de hidrogênio em parceria com empresas e centros de pesquisas internacionais.

Em 2008, e no âmbito do PTI, a Itaipu lança a Plataforma de Energias Renováveis, com o objetivo de disseminar o conhecimento e comprovar a viabilidade técnica, econômica e ambiental das fontes renováveis - solar, eólica, de biomassa e hidráulica. Algumas unidades de demonstração foram implantadas na região oeste do Paraná, como a Granja Colombari, especializada em suinocultura, cujos dejetos são armazenados em um biodigestor para a geração de biogás; a Estação de Tratamento de Esgoto (ETE) da SANEPAR, em Foz do Iguaçu, para a produção do gás metano convertido em energia elétrica juntamente com produção de energia solar; a fazenda Iguaçu, no município lindeiro de Vera Cruz do Oeste, uma unidade de produção de biodiesel desenvolvida a partir do óleo de girassol, dentre outras.

Hoje, a Plataforma de Energias Renováveis e o ClH da Itaipu são conveniados com o Programa de Pós-Graduação em Meio Ambiente e Desenvolvimento da Universidade Federal do Paraná por meio de uma Cátedra da UNESCO sobre o Nexo Água e Energia.

R. gest. sust. ambient., Florianópolis, n. esp, p.378-393, dez. 2015. 


\section{CONSIDERAÇÕES FINAIS}

Para e empresa Itaipu Binacional, a água sempre foi considerada a sua matéria prima e as várias estratégias ambientais centraram-se em torno da sua conservação. A fase do reconhecimento dos efeitos ecológicos do projeto foi marcada pela desconfiança de que especialistas brasileiros não estariam tecnicamente preparados para o trabalho.

Com essa visão, foram contratados consultores internacionais, ainda que não familiarizados com a região e sem conhecimentos da relevância social e cultural dos componentes ambientais que seriam provavelmente afetados. Até 1985, a administração da empresa Itaipu Binacional sofreu fortemente a influência do regime militar brasileiro e paraguaio, caracterizado pelo autoritarismo, verticalidade, modelo tecnocrático de gestão e desmobilização da sociedade.

A Doutrina de Segurança Nacional (DSN), como base ideológica do regime, focava predominante no crescimento econômico, na modernização e na industrialização, em detrimento à conservação ambiental. Qualquer mobilização em torno de assuntos ambientais era tida como perigosa, particularmente se pudesse se transformar num confronto político em que a legitimidade do regime pudesse ser questionada.

Alguns meses antes do preenchimento do reservatório de Itaipu, o movimento Quarup Sete Quedas reuniu, durante mais de três dias, quase 8.000 pessoas num acampamento próximo às cataratas. Para expressarem o seu descontentamento, mas evitando a repressão violenta por parte das autoridades, os participantes transformaram a reunião numa "cerimônia contemplativa de despedida", assemelhando-se mais a um funeral do que a um protesto.

Dentro do próprio governo, os projetos sempre foram apresentados como um fait accompli. As agências ambientais e seus técnicos, que teriam, supostamente, algum poder de decisão, não tinham permissão sequer para exercitar qualquer atividade além de um carimbo de aprovação. A ausência de uma ampla e regulamentada legislação ambiental até 1983 é outro fator adverso, além do que, as condições e meios para sua aplicação eram limitados e desassociados das estratégias de desenvolvimento nacional.

De 1985 a 2003, época em que a consciência ecológica e a legislação ambiental se ampliam, e que as instituições ambientais governamentais se R. gest. sust. ambient., Florianópolis, n. esp, p.378-393, dez. 2015. 
consolidam no país, a Itaipu pode redesenhar sua estratégia ambiental. Além disso, entende que sua área de atuação pode ter outra dimensão e passa a se comprometer com o desenvolvimento regional, ainda que de forma pontual, amparando os municípios lindeiros pelos estragos causados. Nesse período, as preocupações ambientais variaram de acordo com o administrador geral do turno, com as condições financeiras da empresa e dos próprios países parceiros, mantendo o viés conservador nas políticas ambientais.

Uma nova estratégia ambiental é impulsionada de 2003 a 2015, podendo ser considerada revolucionária para o atual padrão do setor elétrico brasileiro. A maior usina hidrelétrica do Brasil, a Itaipu, lança e apoia uma Plataforma de Energias Renováveis, reconhecendo a crise ambiental planetária, e planeja ações para uma economia regional de baixo carbono.

Promove pesquisas e implanta projetos demonstrativos no campo das fontes renováveis de energia, desempenhando um papel proativo, na qualidade de empresa binacional e responsável pelo desenvolvimento regional. São projetos que envolvem o nexo água-energia-alimentos, que merecem ser acompanhados sob o ponto de vista de sua viabilidade e replicação em outras áreas geográficas do país e no exterior, como, de fato, vem ocorrendo com a sub-bacia do rio São Francisco Verdadeiro na Bacia do Paraná 3.

Em entrevista dada à TV Band em maio de 2015 (BAND ENTREVISTA, 2015), o Diretor-geral Jorge Samek vislumbrou um cenário daqui a 70 ou 100 anos, no qual seria possível abrir as comportas de Itaipu, possibilitando que o rio Paraná voltasse ao seu leito natural, recriando as Sete Quedas e uma extensa área que poderia abrigar um parque ou uma agricultura de qualidade. A Itaipu se tornaria um museu para mostrar como os antigos produziam energia. Samek aponta que o desenvolvimento tecnológico avançará no sentido de melhorar a produção das energias renováveis, principalmente a eólica, a solar e a biomassa. Certamente, ainda temos um grande caminho a percorrer na produção de energias renováveis e o futuro parece apontar para isso.

\title{
FROM RESERVOIR FORMATION TO THE ESTABLISHMENT OF THE PLATFORM OF RENEWABLE ENERGIES: 40 YEARS OF ENVIRONMENTAL STRATEGIES IN ITAIPU BINATIONAL DAM
}

\author{
ABSTRACT \\ R. gest. sust. ambient., Florianópolis, n. esp, p.378-393, dez. 2015.
}


Conceived as a project for electricity production in the Parana River, the construction of Itaipu Binational took place during the military governments of Brazil and Paraguay, in the decade of 1970. The closing of the gates of the diversion channel in 1982 generated the great lake of Itaipu, with 1,350 square kilometres of extension, causing huge impacts on the physical, biotic and anthropic environment, changing the geography of western Parana and flooding large tracts of native forests in the Paraguayan territory. Over those 40 years of existence, it is possible to contextualize the environmental strategies of this company, identifying four distinct phases. This article describes these phases, which began in 1975 and are renovated on the recent establishment of the Itaipu Platform of Renewable Energies in 2008 that stands out for developing projects that encourage the use of renewable energy sources - solar, wind, biomass and hydraulics. Today, the platform and the International Centre for Hydroinformatics $(\mathrm{CIH})$ are supported by a UNESCO Chair on Water and Energy Nexus in the Post Graduate Program in Environment and Development of the Federal University of Parana.

KEYWORDS: Itaipu; Environmental strategy; Renewable energy; Management model.

\section{REFERÊNCIAS}

BAND ENTREVISTA. Entrevista com Jorge Samek. Brasil. Band, 2015. Disponível em: <https://www.youtube.com/playlist?list=PLpTOQaQgyYbKShNNjcUhEdJa5BVGD03t>. Acesso em: 15 out. 2015.

BLEY JUNIOR, C. J. Cadastro Técnico Multifinalitário, uma ferramenta gerencial para a integração de critérios de gestão territorial e gestão ambiental: o caso da Itaipu Binacional. 2006. Dissertação (Mestrado em Engenharia Civil) - Centro Tecnológico, Universidade Federal de Santa Catarina, Florianópolis.

BRASIL. Lei n 4.771, de 15 de setembro de 1965. Código Florestal. Brasília,1965.

BRASIL. Decreto Legislativo $n^{\circ} 23$, de 1973. Tratado entre a República Federativa do Brasil e a República do Paraguai para o Aproveitamento Hidrelétrico dos Recursos Hídricos do Rio Paraná. Brasília, 1973.

BRASIL. Lei $n^{\circ}$ 6.938, de 31 de agosto de 1981. Dispõe sobre a Política Nacional do Meio Ambiente, seus fins e mecanismos de formulação e aplicação, e dá outras providências. Brasília, 1981.

R. gest. sust. ambient., Florianópolis, n. esp, p.378-393, dez. 2015. 
BRASIL. Lei n 7.990, de 28 de janeiro de 1989. Institui, para os Estados, Distrito Federal e Municípios, compensação financeira pelo resultado da exploração de petróleo ou gás natural, de recursos hídricos para fins de geração de energia elétrica, de recursos minerais em seus respectivos territórios, plataformas continental, mar territorial ou zona econômica exclusiva, e dá outras providências . Brasília, 1989.

BRASIL. Lei $\mathbf{n}^{\circ} \mathbf{8 . 0 0 1}$, de 13 de janeiro de 1990. Define os percentuais da distribuição da compensação financeira de que trata a Lei $\mathrm{n}^{\circ} 7.990$, de 28 de dezembro de 1989, e dá outras providências. Brasília, 1990.

COMISSÃO MISTA TÉCNICA BRASILEIRO-PARAGUAIA. Reconhecimento dos Efeitos Ecológicos do Projeto (Informe Especial n 4). Foz do Iguaçu: [s.n.], 1973.

CONAMA. Resolução CONAMA n 001, de 23 de janeiro de 1986. Brasília, 1986.

DIAS, R. S. et al. Utilização de ferramentas livres para gestão territorial do nexo água e energia. Desenvolvimento e Meio Ambiente, v. 30, p. 109-126, 2014.

ITAIPU BINACIONAL. Plano Básico de Conservação do Meio Ambiente. Foz do Iguaçu: [s.n.], 1975.

ITAIPU BINACIONAL. Plano Diretor do Reservatório de Itaipu. Foz do Iguaçu: [s.n.], 1982.

ITAIPU BINACIONAL. Impactos decorrentes da Formação do Reservatório de Itaipu. Work-shop on Environmental Protection of the Plata Basin. Anais...Foz do Iguaçu: 1991.

ITAIPU BINACIONAL. Plano diretor de gestão ambiental. [s.I: s.n.], 2000.

ITAIPU BINACIONAL. Sala de imprensa. Perguntas frequentes. 2010. Disponível em: <https://www.itaipu.gov.br/sala-de-imprensa/perguntas-frequentes>. Acesso em: 14 out. 2015.

MULLER, A. Ações Sócio Ambientais na Hidrelétrica de Itaipu, Estudo de Caso. Foz do Iguaçu: Itaipu Binacional, 1982.

MULLER, A. Perguntas e Respostas sobre o Meio Ambiente e Usos Múltiplos do Reservatório de Itaipu. Foz do Iguaçu: Itaipu Binacional, 1985.

O ESTADO DE SÃO PAULO. Falar em preservação era poesia (Entrevista Arnaldo Carlos Müller, engenheiro florestal). 28 nov. 2012.

SMA/ITAIPU. Organização, Meios e Planos. [s.I: s.n.], 1990.

SOUZA, P. P.; MILLS, J. Conflitos Jurídicos Econômicos e Ambientais. Maringá: Editora Universidade Estadual de Maringa, 1995.

R. gest. sust. ambient., Florianópolis, n. esp, p.378-393, dez. 2015. 